\title{
La conquista del texto mediante la combinación de métodos didácticos y literarios
}

The conquest of the text by means of the combination of didactic and literary methods.

Lic. Diana de la Caridad Cervantes Almaguer. Profesora asistente. dicealma@ult.edu.cu

MSc Ariagna Alamo Vega.

Profesora Auxiliar. Universidad de Las Tunas. ariagnaav@ult.edu.cu

Dr. C. P Alejandro CruzataMartínez.

Docente-Investigador. Universidad San Ignacio de Loyola. Lima. Perú. alejandrocruzatamartínez@yahoo.es

Recibido

09/ 08/2018

Revisado 12/09/2018

Aceptado 20/10/2018

\section{RESUMEN}

- I artículo propone una guía para el estudio del poema - Dos milagros, de José Martí, desde una perspectiva integradora, en la combinación de algunos de los métodos conocidos para el análisis literario, tanto desde la Didáctica como desde la Literatura. Su supuesto básico es la necesidad de comprensión del sentido de la acción social en el contexto del mundo, en este caso desde el pensamiento martiano que es expresado, en toda su obra con una genialidad única en su tiempo. En la investigación que sirvió de base para este artículo, se usó el método cualitativo de análisis de texto que consiste en analizar el discurso y descubrir la intensión del autor desde lo hermenéutico y su relación con otros textos del propio autor. La propuesta se apoya en los enfoques cognitivo, comunicativo y sociocultural, transcurriendo por los niveles adecuados para el logro de la comprensión, lo que facilita además, la reflexión acerca de los puntos de convergencia y divergencia del texto con la estética modernista y la vigencia humanista del pensamiento martiano.

Palabras claves: Dos milagros, niño travieso, mariposa, sicomoro, estero, ave de oro. 


\section{SUMMARY}

The article proposes a guide for the study of the poem Dos milagros, by José Martí, from an integrating perspective, in the combination of some of the known methods for literary analysis, both from the Didactics and from Literature. His basic assumption is the need to understand the meaning of social action in the context of the world, in this case from the Martian thought that is expressed, in all his work with a unique genius in his time. In the research that served as the basis for this article, the qualitative method of text analysis was used, which consists in analyzing the discourse and discovering the author's intension from the hermeneutic and its relationship with other texts by the author himself? The proposal is based on the cognitive, communicative and sociocultural approaches, passing through the appropriate levels for the achievement of understanding, which also facilitates reflection on points of convergence and divergence of the text with modernist aesthetics and humanist validity of Martian thought.

Keywords: Two miracles, naughty boy, butterfly, sycamore, estuary, golden bird. 


\section{UNA VÍA PARA EL ANÁLISIS INTEGRAL DEL TEXTO}

La conquista del texto literario por parte del lector, que como bien sabemos puede devenir autor de otro texto, en tanto produzca nuevos significados, no llegará a ser veraz sin la eficacia de la lectura como primera mirada y el necesario tránsito por todos los niveles de la comprensión, continuando por el análisis y la construcción, es decir, el andar consciente y placentero por el camino que nos brindan los componentes funcionales del enfoque cognitivo, comunicativo y sociocultural." (Romeu, 2007). No son pocos los autores que han teorizado sobre los métodos desde la didáctica y desde la ciencia literaria, como por ejemplo este resumen de Mañalich (2002) quien define y a la vez analiza: los métodos y procedimientos pedagógicos deben lograr, como tendencia, una armónica conjunción con los métodos de la ciencia (historia, teoría y crítica), y el aporte de estos a la asignatura Metodología de la Enseñanza del Español y la literatura, que se ajusta a un arreglo didáctico. (p. 23)

Sin embargo, la selección de métodos y las potencialidades que la oportuna combinación que ellos nos brindan, aún no se aprovecha lo suficiente en el proceso de enseñanza aprendizaje de Literatura. Es por ello que se hace necesario recurrir a todo cuanto pueda enriquecer la propuesta de análisis en la búsqueda de integralidad del mismo, con una visión contemporánea.

El presente trabajo tiene como objetivo proponer una guía de análisis para el poema Dos milagros, de José Martí Pérez, en la cual se han combinado varios métodos didácticos y literarios, según la naturaleza del texto objeto de estudio, cuya aplicación permite la visión integral a la que hacíamos referencia, desde los presupuestos del enfoque.

Los autores de este artículo, planteamos que, mediante la combinación de diversos métodos de análisis, tanto los contemplados por la didáctica, como los que aparecen fundamentados por los estudios literarios, puede llegarse a la integralidad que requiere la apropiación de la comprensión del texto, y así ofrecer las vías idóneas para que los educandos sean capaces de reaccionar ante el hecho literario desde una primigenia mirada al referido texto, esperada o inusitada, hasta esa profunda sensación de ganancia que puede llegar a experimentar. 


\subsection{Acercamiento teórico a los métodos empleados}

Desde la didáctica, esta propuesta integra métodos y procedimientos como los siguientes:

Primero: Análisis según los componentes primordiales del contenido y la forma; vía que nos permitió centrarnos en la estructura, el estilo, las relaciones entre los personajes, el sistema de imágenes y metáforas, entre otros, y conducir el análisis hacia la aplicación de los principios de integridad y de unidad de contenido y forma. Nos facilitó la integración de las categorías líricas, aunque no es exclusivo de este género.

Segundo: Método heurístico desarrollador de la actividad cognoscitiva en la percepción más profunda de la obra literaria con el propósito de proporcionar a los estudiantes modos de actuación para el análisis la puesta en práctica de dichos modos de actuación a nuevas situaciones. Como procedimiento empleamos la conversación heurística mediante un sistema de preguntas teniendo en cuenta que cada respuesta posibilitara la transición lógica a la siguiente pregunta.

Tercero: Método de lectura creadora: el cual nos permitió el vínculo con lo cognitivo afectivo, y el desarrollo de las actitudes artísticas y la sensibilidad de los estudiantes. El procedimiento usado fue específicamente la lectura expresiva.

Desde los estudios teóricos literarios, la guía se estructuró sobre la base del análisis por los tres planos o niveles del texto y se combinaron otros métodos actuales más empleados en Cuba, dígase, el método lingüístico, el semiológico, el sociológico y el intertextual. No declaramos de manera independiente el método biográfico, porque el tratamiento de estos contenidos es punto de contacto entre los tres primeros métodos seleccionados, al igual que el arribo a conclusiones, juicios, la realización de valoraciones y la búsqueda de la vigencia.

Claro que la aplicación combinada de estas vías de análisis, no se materializan en el tratamiento de cada uno de los elementos que los conforman, sino de aquellos que brindan una utilidad para el texto objeto de estudio, pues cada uno de ellos requiere un abordaje según su contenido y potencialidades.

El método lingüístico nos permitió el análisis de la semántica, medios lingüísticos, figuras y tropos, y la gramática del texto, el tratamiento acústico y métrico y los elementos pragmáticos. Aquí se combinan, de manera fluida las dimensiones semántica, sintáctica y pragmática del enfoque. 
El método semiológico nos adentró en el tratamiento de los códigos del texto, símbolos, significación, contexto y la recepción de la obra dentro del mismo. Elementos de la estructura (métrica) y su significación. También desde el enfoque psicológico es posible el tratamiento de los símbolos que aparecen en el texto.

El método sociológico nos llevó a la profundización en los datos del autor y el marco histórico-social y político en que se desarrolló, su visión reflejada a través de la obra y la pertenencia del texto a un movimiento literario determinado.

El método intertextual nos permite establecer la relación con otros textos que constituyen referentes literarios y artísticos. Este se emplea desde el punto de partida de la clase, y posteriormente se retoma en el desarrollo de la guía.

\subsection{Secuencia metodológica para la clase:}

Para garantizar la calidad del análisis de la obra y por ende de la clase práctica, elaboramos y entregamos previamente una guía de actividades. Las cuatro primeras actividades, se encaminan a la investigación y revisión de contenidos teóricos que servirán de preparación básica para enfrentar el análisis, la quinta y más extensa, es la guía de análisis del texto poético en cuestión.

Esta guía contiene un amplio número de preguntas, de las cuales, no todas tienen que conformar la propuesta para el desarrollo de la clase. El docente tiene la libertad de hacer una selección en dependencia de los factores objetivos que marcarán el desarrollo de su clase y llevarla al aula, lo que no debe ofrecer dificultades.

En la misma, aparecen como anexos los contenidos acerca de la silva modernista abordados por Manuel Gayol Fernández, en Teoría Literaria.

A continuación, reproducimos la misma para ganar en claridad acerca de lo abordado:

1. Resume los datos biográficos de José Martí, relacionados con la publicación de la Edad de Oro, el Modernismo, y su pensamiento independentista y de fe en el progreso de América.

2. Investiga qué representa el sicomoro en la cultura egipcia.

3. Revisa los conceptos de antítesis, símbolo e imagen para que recuerdes en qué consisten y para qué se emplean. 
4. Del poema Dos milagros, descifra las siguientes incógnitas léxicas: bribón/ estero/ sicomoro/ milagro/ travieso/ madero.

5. Lee detenidamente el poema Dos milagros, de José Martí y responde:

Antes de comenzar a desarrollar el contenido de la guía, tal como está concebido en la clase, quisiéramos detenernos en dos momentos fundamentales. Primero, el aseguramiento del nivel de partida para lo cual se tomó la siguiente cita martiana: "La naturaleza inspira, cura, consuela, fortalece y prepara para la virtud al hombre. "José Martí.

La cita se escribió en la pizarra y a partir de su lectura y comentario, se dio tratamiento a la estrategia medioambiental, lengua materna, política- ideológica; además de los componentes de la asignatura y comienza ya la aplicación del método intertextual, en este caso desde la intertextualidad, pues el fragmento trata el tema de la naturaleza dentro de la misma producción literaria martiana.

Brevemente se puede precisar si hubo alguna dificultad con el desarrollo de las preguntas de la guía y el tratamiento ortográfico, caligráfico y ontológico de las tres incógnitas léxicas, usando como medio la pizarra.

Una vez declarada la temática y hecha la orientación hacia el objetivo como principio didáctico, se retoma el título del poema "Dos milagros" para trabajar la estrategia de anticipación al texto. Luego las ideas expresadas por los estudiantes, según lo que les sugiere el título, se retomarán en las últimas preguntas de la guía para, junto a toda la otra información sustraída del texto, establecer la relación de título y contenido.

El desarrollo de la guía se introduce con la lectura modelo por parte del profesor. Lee detenidamente el poema Dos milagros, de José Martí: ¿De qué se habla en el poema? ¿Qué sentimientos o sensaciones te produjo? ¿Qué es lo que más te gustó de esta primera lectura? ¿Cuál es la idea central del poema?

Estas preguntas se encaminan a la recreación de un clima propicio para la lectura y el análisis donde el estudiante comienza a comprometerse con el primer nivel de la comprensión del texto, a buscar dentro y de manera consciente, qué ha provocado esa primera lectura en él.

Posterior a la identificación del creador, se prosigue con interrogantes que buscan el acercamiento biográfico mediante datos del autor que se vinculan al texto ¿En qué parte de la obra martiana podemos encontrar estos versos? ¿Para quiénes fueron 
escritos? ¿Sabes en qué circunstancias de la vida de Martí surge esta publicación y a qué necesidad responde? Comenta.

Los estudiantes deben reconocer La Edad de Oro como la publicación que incluye este texto y ser capaces, sobre lo investigado, de comentar que estuvo dirigida a los niños y que respondió a la necesidad que Martí vio de cambiar desde la literatura, los modelos éticos y de su época, por otros, menos dogmáticos y más didácticos, reflexivos, humanistas, y comprometidos con su tiempo. Su propuesta es una literatura de alto valor axiológico que divierte, pero instruye. Martí se encontraba en los EUA, sufriendo los rigores materiales y espirituales del exilio y vuelca en esta publicación toda la ternura y el cariño, que la distancia le negaba entregar a su hijo que había quedado en Cuba.

En forma de revista se editan apenas cuatro números, pues la concepción martiana acerca de la formación de valores en la literatura para niños, no se correspondía con los conceptos dogmáticos y exigencias religiosas de la época. (Aunque presente en casi todos los métodos elegidos, estas preguntas responden sobre todo al análisis sociológico)

Luego de tratar las incógnitas léxicas, que se retomarán oportunamente en el contexto del poema, se elige el plano compositivo para continuar adentrándonos en el análisis. Aunque se sugiere fragmentar para retomarlo una vez que se analicen otros aspectos lingüísticos, semánticos y sintácticos necesarios para descubrir rasgos de la estructura vinculados a la semántica. ¿Por cuántas estrofas está compuesto el poema? Mide sus versos y denomínalos. Determina la rima y clasifica la estrofa.

El estudiante debe reconocer que está ante dos estrofas conformadas por dos versos heptasílabos, seguidos de dos endecasílabos, en cada caso. La rima es consonante y alterna. Toda una combinación para nada común; pero, que no debe ser difícil de identificar una vez consultado el material sobre la silva modernista, anexo a la guía de trabajo independiente para la clase.

Nos adentramos ya en el plano lingüístico, combinando el método de análisis lingüístico y las dimensiones del Enfoque. Relee los dos primeros versos de la primera estrofa:

Iba un niño travieso

Cazando mariposas. 
Localiza el primer sintagma nominal (SN) y describe su estructura. ¿Qué figura literaria emplea el autor? ¿Qué te transmite?

Los estudiantes deben reconoce el SN "un niño travieso" conformado por (un) determinante indefinido, (niño) sustantivo y (travieso) adjetivo.

Se trata de un niño que puede repetirse en muchos otros; pues el indefinido (un) no nos precisa, pero sí sabemos que es travieso, inquieto, revoltoso característica común en esa temprana edad. Este sintagma nominal estructura además un epíteto que, en este caso, nos transmite una cualidad inherente del niño.

¿Qué matiz tiene la acción que realiza el niño y qué resultado esperas de ella?

La acción que provoca que el niño sea calificado de travieso, está expresada en una perífrasis verbal, Iba cazando, cuya construcción aparece en una sintaxis alterada, es decir, en un hipérbaton., "Iba (un niño travieso) cazando mariposas". El lector no espera que esta acción tenga un final precisamente feliz. Puede imaginar que cuando menos las mariposas han de quedar confinadas a alguna colección o lastimadas sin querer por la torpeza del niño, o realmente dañadas por una intención malvada. De cualquier forma, privadas de la maravilla de la vida. Tengamos en cuenta que solo sabemos que este niño es travieso. Se retomará la lectura, ahora de los dos segundos versos de la estrofa:

Las cazaba el bribón, les daba un beso,

Y después las soltaba entre las rosas.

¿Qué sustantivo sustituye a la palabra "niño"? ¿Qué es un bribón? ¿Tiene el mismo significado en el texto poético? Explica tu respuesta.

Sabemos que el niño no es solamente travieso es, además, el bribón, característica que reafirma la sospecha que despiertan los primeras versos, acerca de un triste final para la mariposa, súmase a esto la reiteración de la acción que realiza en busca del énfasis. Pero, ¿qué descubrimos en el recorrido por el verso?, pues un bribón sui géneris, un bribón cuya única "maldad" consiste en sentir y besar las mariposas; para luego, liberarlas en su medio natural predilecto: el jardín, un todo, del cual las rosas son la parte anunciada. Es este el momento de retomar el significado del sustantivo bribón y valorar su significación dentro del discurso poético, la connotación que alcanza y que emana de la ternura que el sujeto lírico le imprime y del valor afectivo de modo general. 
Identifica las formas verbales de esta primera estrofa y determina tiempo y modo. ¿Cuál es la intención comunicativa del autor al usar este tiempo para proyectarnos la escena que acontece? Identifica la forma no personal del verbo que aparece y la forma conjugada que procede del infinitivo cazar. ¿Qué le aporta al texto poético este juego de palabras?

Encabezadas por la perífrasis verbal Iba cazando, aparecen, además, cazaba, daba, soltaba, todas en copretérito del modo indicativo. Es evidente que la intención comunicativa del autor es proyectarnos una escena perdurable, continua, desde la simultaneidad expresada en la perífrasis, pues el niño no iba y cazaba, sino iba cazando; hasta las demás formas verbales que aparecen de modo independiente. El juego entre el gerundio y la forma conjugada del infinitivo cazar son claves del énfasis que se busca y de la cohesión entre la idea expresada en los dos primeros versos y los dos últimos.

¿Qué figura literaria aparece en estos versos? Comenta: La imagen es la figura literaria idónea, es capaz de conjugar los sentidos de la vista el tacto y el olfato y nos llega pronta, todo un lienzo cargado de color, luz, perfume y vida.

¿Qué palabras claves de esta estrofa reflejan el amor del niño por la naturaleza? ¿Crees que son símbolos dentro del discurso poético? ¿Por qué?

Pueden señalarse palabras claves o motivos poéticos que van conformando toda una red semántica: mariposas, beso, y rosas. Estas nos permiten hablar de un lenguaje tropológico de compleja significación, pues cada una constituye también un símbolo.

La mariposa representa belleza, delicadeza, fragilidad, alegría y vida. Se asocia a la primavera como estación donde la naturaleza se revitaliza y al igual que la abeja tiene una misión en el ciclo vital, la polinización, es decir engendra vida. En el texto, su vuelo remite a la libertad. Más adelante retomaremos este último elemento. El beso es expresión de ternura, admiración, humildad ante un milagro. La rosa alude a la belleza, la fragancia, también se asocia a la primavera, el orgullo y el amor triunfante. Si nos detenemos en el predominio de fonemas nos percataremos de que prevalecen (las $s$ y b, sonidos suaves y sonoros ideales para recrear el contexto del jardín: el vuelo de la mariposa, el aire, la suavidad de las alas). Esta figura no es otra que la aliteración. El tratamiento del componente laboral nos hace reparar en que, en los contenidos literarios de la enseñanza media este recurso se conoce como armonía imitativa, precisamente por la armonía que logra la repetición intencionada de los 
fonemas. Pero, ¿cuál es el recurso literario que prevalece en la estrofa? ¿Crees que su contraste transita de lo negativo a lo positivo o viceversa?

Sin dudas, otra figura retórica aparece en el concierto maravilloso del lenguaje martiano, en nuestro criterio, para apoyarse en las ya vistas y alcanzar mayor relevancia desde la estructura misma del texto. Se trata de la antítesis que permite contrastar la idea expresada en los dos primeros versos con la de los dos últimos. La mariposa está en peligro inminente de ser cazada y morir sin embargo es cazada, sí, pero tras el regalo del beso del bribón, que solo quiere como recompensa sentirla y admirarla de cerca, es puesta en libertad y no en cualquier sitio, sino entre las rosas. Es un contraste que viaja de lo negativo a lo positivo, de la posible prisión y muerte, a la reafirmación de la vida y la libertad.

Todas las preguntas anteriores permiten que los estudiantes estén en condiciones de reconstruir la imagen de este niño y valorar su actitud.

Se retoma la lectura de la segunda estrofa teniendo en cuenta una secuencia similar a la de la primera estrofa para continuar el análisis. Relee los dos primeros versos de la segunda estrofa.

Por tierra, en un estero,

Estaba un sicomoro,

¿Qué significado literal tienen los sustantivos: estero y sicomoro? ¿Con qué cultura milenaria se relaciona el sicomoro y qué significación tiene en ella?

El estero es un charco pantanoso, bajo, producido por la penetración del agua de las mareas y el sicomoro o sicómoro, (debe trabajarse esta palabra en la pizarra) es un árbol frondoso, de madera incorruptible. El sicomoro tiene una gran significación en la cultura egipcia, es famoso un jeroglífico donde aparece un par de ellos representando las puertas de la vida, y el sarcófago de Osiris, rey supremo de esta cultura, se construyó de esta madera. Por tanto, estamos ante un referente cultural exótico, de suma importancia, casi insustituible en este contexto debido a su carga semántica.

Pero volvamos a la estructura del verso. ¿Qué clase léxico-sintáctica de palabra le da inicio? ¿Qué tipo de complemento introduce? (Detengámonos aquí) "Por" es la preposición que inicia el verso e introduce un complemento circunstancial de lugar que nos ubica en el sitio exacto donde se encontraba el sicomoro. El autor no utiliza la preposición en, es sabido que los árboles están plantados en tierra "si son 
portadores de vida en su relación con ella", pero el sicomoro está por tierra; no se necesita mucho más para entender que está caído, privado de la vida.

¿Qué recurso literario se utiliza en estos dos versos y qué te transmite? Los dos versos integran una imagen, muy distinta a la primera imagen de la estrofa anterior, donde solo la mariposa ya anunciaba el color y la alegría. Aquí se nos presenta un estero con toda su significación literal, que nos transmite fealdad, un tono gris; tal vez, con un aire viciado de salitre y estancamiento. A la representación plástica se añade un tronco caído, ya sin vida, que denota tristeza, muerte, fin, decadencia.

¿Identifica la forma verbal que aparece en estos dos primeros versos? ¿Coincide con el tiempo y modo de las FV de la primera estrofa? Encontramos la forma verbal estaba, al igual que las FV de la primera estrofa en copretérito del indicativo, lo que hace que continuemos sintiendo la perdurabilidad de la acción que se realiza.

Es necesario ahora retomar los dos últimos versos para su lectura, pero esta vez se pedirá a los alumnos que realicen una lectura en silencio, debido a que la imagen que encontrarán presenta, un mayor grado de elaboración.

Le da un rayo de sol y del madero

muerto sale volando un ave de oro.

Localiza en los dos últimos versos el sintagma nominal que sustituye a sicomoro.

El autor establece un nexo entre el sicomoro y "el madero muerto", que no solo funciona aquí como elemento de cohesión, sino que nos confirma, por si han quedado dudas, que el sicomoro yace sin vida en el estero.

¿Qué acción de la naturaleza recae en él y qué consecuencias tiene? Ahora, Un rayo de sol interactúa con el madero y de él sale volando un ave de oro. Aparecen nuevos símbolos: el sol, es fuente de energía, vida, luminosidad y calor; el ave representa el vuelo, la libertad, y el oro, algo elevado, valioso en su pureza y belleza, luminosidad, asociado a la creación de nuevas formas, es decir, a la transformación artística.

¿En qué estructuras léxico-sintácticas se concentran estas acciones? ¿Qué cambios observas con respecto a los verbos empleados en los versos anteriores en cuanto al tiempo? ¿Qué intención comunicativa adquiere la perífrasis verbal que aparece en el texto? 
La forma conjugada da, y la perífrasis sale volando, establecen un cambio en el tiempo con respecto al resto del discurso. En la inmediatez del presente de indicativo, el rayo de sol "le da", incluso la acción aparece antepuesta precisamente en el punto donde se produce un giro total en el empleo del tiempo verbal, sin dudas es importante que lo primero sea advertir este cambio, como una convocatoria para asistir al hecho que se está produciendo de manera inmediata. La intención comunicativa, en cambio, sigue siendo la misma, el ave no sale y vuela, sino sale volando, es una acción simultánea y dinámica que nos impacta, al mismo tiempo que sale vuela y se libera, al igual que la mariposa, de la prisión y la muerte. "Resulta evidente para el trabajo con la comprensión que los elementos de la forma, el código con su estructura sintáctico gramatical no pueden verse aislados sino fundidos al diálogo intratextual, semántico y pragmático." (Sales, 2010, p. 60)

\section{¿Qué otros recursos literarios encontramos en estos dos versos? ¿Qué aportan?}

Estamos ante el estremecimiento inevitable que despierta esta imagen. Un rayo de sol, cargado de energía provoca un cambio en la triste realidad del madero sin vida, "un único rayo es suficiente", para lograr la maravilla del ave en vuelo y no de un ave cualquiera sino, un ave de oro, que despliega en su vuelo luz y belleza en busca de la libertad y la vida. La imagen se ilumina por el rayo sol y el resplandor del oro y rompe el gris de la neblina del estero.

¿Con qué referente de la mitología puedes relacionar esta imagen? El tratamiento de la intertextualidad es propicio para establecer relaciones que faciliten la producción de significados del texto. En este caso, los estudiantes pueden mencionar al mito del ave fénix, símbolo de resurrección, purificación e inmortalidad, también vinculado a las culturas egipcia, árabe e hindú. Se consumía por acción del fuego cada 500 años y luego resurgía de sus cenizas con plumaje, anaranjado, rojo y amarillo incandescente.

El predominio del fonema r y alguna t, delatan que al autor insiste en el recurso de la aliteración para lograr una sonoridad que esté a tono con la realidad que se recrea. Refuerza la imagen a partir de la sensación de ruido (tal vez de la caída del madero), aspereza (del madero y la tierra, tal vez roca, pues recordemos que los esteros están en zonas costeras),

¿Qué recurso literario prevalece en la estrofa completa? Es evidente que aunque encontramos metáfora, imagen, epíteto, aliteración, símbolo; las dos estrofas están estructuradas sobre la base de la antítesis, la contraposición de conceptos: vidamuerte, belleza-fealdad, tristeza-alegría, luz-opacidad. 
¿Los contrastes expresados van de lo negativo a lo positivo o viceversa? ¿Qué relación guarda la manera de emplear este recurso con el pensamiento del autor y con su época? En ambas estrofas, los contrastes evolucionan en un tránsito hacia lo positivo; en consecuencia con la visión martiana del futuro y su fe inquebrantable en un destino mejor para la América, justo cuando la realidad de los pueblos latinoamericanos era cada vez más nefasta y convulsa. A diferencia de las antítesis casalianas, que por lo general viajan en sentido inverso, Martí, por solo comentar un ejemplo, no pudo concebir el águila herida sino sobrevolando el azul sereno (triunfo/vida/libertad), mientras la víbora del veneno moría en su propia guarida (derrota/muerte/fin)

Oportuno sería entonces, invitar a los estudiantes a releer los dos primeros versos de cada estrofa y colocarlos ante una variante de selección múltiple para V o F a partir de las siguientes afirmaciones:

- El autor emplea dos imágenes.

- El sujeto lírico se lamenta de lo que ocurre.

- El sujeto lírico solo nos presenta dos situaciones comunicativas que le sirve de punto de partida en cada estrofa.

- Para el sujeto lírico es importante declararnos por qué ocurre lo que se describe en estos versos.

- Estos son los versos más extensos del poema.

Luego, motivarlos a indagar sobre ¿Qué información se agrega en los dos versos finales de cada estrofa? ¿Qué importancia le concedes? ¿Cómo es la extensión de estos versos con respecto a los anteriores?

Permitiría profundizar en la estructura de la antítesis desde el punto de vista conceptual y estructural, además de acercarlos a un destino que solo puede ser visitado por el descubrimiento de la semántica del texto.

¿Crees que la alternancia de la métrica y su relación con las ideas que se expresan, tienen una significación especial? Explica. Sí, en efecto se han empleado dos imágenes muy sencillas y breves, como si la intención no fuese decir más, ni tomar partido ante la acción, ni declararnos la causa, sino mostrarnos una realidad muy específica como punto de partida en los versos más breves (heptasílabos) de cada estrofa. Logran estos versos ubicarnos en el escenario seleccionado para el asunto a tratar. Por el contrario, los dos versos finales de cada estrofa (perfectos endecasílabos) permiten 
ampliar el discurso poético con la belleza suprema del lenguaje connotativo, y el recurso eficaz de lo extraordinario; lo insólito contenido en el milagro que tal vez, muchos lectores aguardan desde el principio. He ahí la razón y significación de la alternancia de la métrica que debe ser descubierta de a poco por los alumnos mediante el orden de las interrogantes.

La intertextualidad ha sido tratada a partir de la propia obra martiana, es decir, se ha concebido desde la propia relación intratextual.

"La naturaleza inspira, cura, consuela, fortalece y prepara para la virtud al hombre." José Martí. ¿Existe relación entre esta cita martiana y el poema? Argumenta tu respuesta.

La naturaleza es obra majestuosa y bella que inspira al hombre para la creación subjetiva y objetiva, que cura el espíritu en la medida que consuela y sosiega y cura el cuerpo por todos los beneficios materiales que se obtienen de ella. La relación del hombre con ella es vital; ya que, el hombre se transforma en la medida que la transforma y domina; el hombre crece en ella, se vuelve fuerte, se ennoblece de alma aprendiendo a amarla y a amar su trabajo y a sus semejantes. Crece amando la vida, lo posible y lo imposible, creando, construyendo, conquistando. En ambos textos, hay un mensaje de esperanza, de reafirmación de la vida y los sentimientos más nobles, de la virtud.

Resume en no más de cuatro líneas el asunto del poema. ¿Cuál es, según tu punto de vista, el tema del poema? Comenta con tus compañeros la idea que te ha dejado el poema. ¿Qué importancia le concedes al tratamiento de esta idea, en la literatura para niños de la época donde fue escrito el texto? ¿Qué vigencia tiene esa idea en ti y en la sociedad que, también tú construyes?

El tratamiento de las categorías asunto, tema e idea, todas incluidas en el plano ideo-temático, puede encausarse mediante el anterior grupo de preguntas, con un enfoque cognitivo, comunicativo y sociocultural que despierte la reflexión acerca de la utilidad y aplicación de lo estudiado y la vigencia del legado martiano en la ideología humanista, progresista y revolucionaria que debe caracterizar a un profesional de la educación en nuestra sociedad socialista.

Tanto el método sociológico, como el psicológico, el semiológico, el dimensional y el estilístico, nos permiten analizar la repercusión de la obra en su contexto y fuera de él. 
Con La Edad de Oro, de modo general, Martí supo sortear muy bien los dos errores más frecuentes de su tiempo en el campo de la literatura infantil, donde se peca por exceso o por defecto. Ni sobrestima ni subestima a los niños. No les habla como dómine, en tono retórico ni en forma aniñada y falsa, no lo puede hacer con quienes considera merecedores de la verdad y la belleza "para que no les salga la vida equivocada". Escribe sin paternalismos, eleva su escritura a un lugar donde es necesario nombrar de nuevo las cosas, y no solo entretener sino instruir. En el texto objeto de análisis, como en tantos otros, la idea se vincula a lo axiológico, al desarrollo de valores de modo espontáneo, natural y consciente, no condicionado por el pensamiento escolástico que permeaba la enseñanza de la época.

¿Qué relación existe entre el título y el resto del contenido del poema? Aunque esta interrogante puede haber sido respondida por algún estudiante en el transcurso del análisis, es importante retomarla como cierre para darles la participación a otros estudiantes que arribaron más tardíamente a este nivel de conclusión.

Cada una de las estrofas contiene un milagro, tal y como se anuncia en el título y como se abordó al emplear la estrategia de anticipación, al inicio del análisis. En cada una de ellas sucede un hecho inesperado, insólito, maravilloso que nos conmociona; una transformación total de lo esperado en lo impensado y superior, en el milagro.

¿En qué medida este poema es representativo del Modernismo, y en qué medida no lo es? Justifica. La aplicación del método sociológico, nos permite valorar la obra como exponente de una escuela, tendencia o movimiento artístico-literario. Es importante detenernos en algunas consideraciones. Martí inicia en 1882, el movimiento modernista con una nueva estética cuyo máximo exponente dentro de su obra fue Ismaelillo.

Si bien Martí, evoluciona hacia una producción literaria que desde el punto de vista conceptual va a estar más comprometida con su realidad inmediata, con un profundo humanismo y latinoamericanismo, que la vuelve parte indisoluble de su contexto histórico; esta sigue desde sus esencias formales respondiendo a un lenguaje preciosista, refinado, con el empleo de cultismos y la construcción de la imagen plástica, cromática, vigorosa e iluminada. El desapego que tuvieron los modernistas por su realidad inmediata, al menos en su primera etapa, no lo vamos a encontrar en Martí, ni el regodeo en la melancolía y el pesimismo; no es poeta de las torres de marfil, no de contextos exóticos más allá de la necesaria alegoría. Con la perfección y preciosismo del mármol, no dibuja las fuentes de los cisnes en jardines de castillos y princesas, sino las estatuas de los héroes sagrados de la patria, por 
solo poner un ejemplo; pero reforma en el verso, emplea la musicalidad, el símbolo, los neologismos y esto podemos verlo en la prosa de Amistad Funesta, de su crítica de arte, de su diario de campaña, de su amplio epistolario, de su ensayística, de su oratoria y en su lírica hasta su teatro escrito en versos, donde, además es innegable la supervivencia de presupuestos estéticos que en ocasiones tienen sus raíces dentro del Romanticismo y otras dentro del Realismo.

Entonces en Dos milagros encontramos la imagen sugerente de luminosidad, cromatismo, olor, descriptiva hasta la representación plástica; el exotismo de la segunda estrofa, puede ser camino para resaltar el valor de los elementos identitarios en alegoría a nuestra cultura y reafirmar a la vez el contraste como técnica; ya que, se contrapone a la visión de un jardín o campo perfectamente cubano, donde juegan niños y vuelan mariposas entre flores. La musicalidad es otra característica que se logra no solo mediante la distribución de los acentos en los versos y la alternancia perfecta de heptasílabos y endecasílabos, sino mediante la cadencia de la aliteración. El empleo de símbolos y la renovación de la métrica, en este caso de la silva.

Pero es precisamente en su visión y mensaje donde esta esencia modernista se disipa. Digamos que es un poema optimista, esperanzador, sus imágenes señalan el triunfo y la vida, la libertad; en él la luz rompe opacidades, el vigor de lo nuevo se impone ante la decadencia, no hay melancolías, ni pesimismos ni evasiones. Es claro que el milagro es posible, un "por llegar", mucho mejor, triunfo del mejoramiento humano en el cual Martí había afirmado su fe.

La combinación de métodos didácticos y particularmente de análisis literario, en una guía de interrogantes, organizada de manera gradual, coherente, en su tránsito por los niveles de comprensión del texto, y concebida desde un enfoque cognitivo, comunicativo y sociocultural; permiten llegar con mayor eficacia a los territorios de la lectura y profundizar en el análisis del texto objeto de estudio como exponente de la época, movimiento, escuela o tendencia que prestigia, así como la expresión y vigencia del ideario del autor. Cada método aporta un complemento indispensable ya sea desde la forma o desde contenido y por separado, ninguno de ellos permitiría alcanzar la integralidad, de la cual requiere la preparación para la verdadera conquista del texto literario. 


\section{REFERENCIAS}

Roméu, Escobar, A.(2007) El Enfoque Cognitivo, Comunicativo y Sociocultural en la enseñanza de la lengua y la literatura. La Habana: Ed. Pueblo y Educación.

Hernández, J. E. (et al). (2011).Introducción a los estudios literarios. La Habana: Ed. Pueblo y Educación.

Mañalich, R. (2007). La enseñanza del análisis literario: una mirada Plural. Cuba: Ed. Pueblo y Educación.

Martí, J. (2007).Obras Completas Edición Crítica. La Habana: Centro de Estudios Martianos.

Montaño Calcines, J. R. (2008). Temas de actualización Literaria. Cuba: Ed. Pueblo y Educación.

Navarro, T. (1966). Métrica Española. La Habana: Edición Revolucionaria. . (1985). Textos y Contextos. La Habana: Ed. Arte y Literatura. 
